\title{
The effect factors of the second digital divide among the college students
}

\author{
Fan-Bin Zeng \\ College of Journalism and Communication, Jinan University Guangzhou, China, 510632 \\ E-mail: zengfanbin@vip.sina.com
}

\begin{abstract}
Based on a survey on students of Jinan University $(\mathrm{N}=302)$, this study focuses on the factors of Internet usage---the second digital divide among college students. The survey shows that birthplace has great positive effects on the time of Internet usage among students. And the motivation of Internet based on uses and gratification theory has great positive effects on the index of Internet usage about studying and working. Especially, the emotional factors of Internet using, including the attitude toward the Internet and the Internet self-efficacy, have great positive effects on the level of Internet usage, including the time of Internet usage and the index of Internet usage about studying and working
\end{abstract}

Keywords: Second digital divide; Knowledge gaps; Uses and gratification; Attitude; Internet self-efficacy

\section{INTRODUCTION}

Digital divide can be divided to two kinds: The first Internet access on the digital divide refers to the gap, also known as "accessing divide"; the second digital divide exists between the Internet usages, also known as "using divides". The study of the second digital divide mainly focuses on the following aspects: (1) the socio-demographic factors of Internet use. For example, Fox and Madden find that young people tend to use more communication and interaction tools compared with other age groups based on the analysis of age between different Internet users ${ }^{[1]}$. (2)The psychology factors of Internet using. Hamburger concluded that outward-looking men prefer to use the Internet for leisure activities, but nervous women are more like using social networking services ${ }^{[2]}$. (3)Analyzing the social network of Internet use, Rojas found that the negative attitudes of relatives and friends of using the Internet play a negative role in poor families and young people of Spain ${ }^{[3]}$ Therefore, The purpose of this study selects college students as an example for the empirical analysis, takes a comprehensive measure of the second digital divide, and analyzes the various factors,.

\section{THEORETICAL FRAMEWORK AND HYPOTHESES}

\section{A、 "Knowledge gap"}

According to the theory of "knowledge gap" in 1970, P.J.Tichenor argued that with the increasing information disseminated to the society by mass media, people with different socio-economic status got the media knowledge at different levels. People with higher socio-economic status will be faster to get such information than those with lower socio-economic status. The theory developed into a complete theoretical framework later. The factors affecting the knowledge gap were sorted into two major aspects, that is, macro level (community, social and national levels) and individuals level (individual's subjective sense). At the macro level, socio-economic conditions will determine the existence of the knowledge gap in the different groups. For undergraduates, their socio-economic situation correlates to their birthplace, educational level of their parents and other family-related socio-economic backgrounds. Individual factors which including education, knowledge of Internet will played an important role in the formation of the knowledge gap. According to this theoretical framework, we conclude the following hypothesis: 
Hypothesis 1: the higher their Parents' level of Education, the higher the level of their Internet usage.

Hypothesis 2: Students born in urban have a higher level of Internet usage than those born in rural.

Hypothesis 3: The higher the Educational level of students, the higher the level of their ability to use Internet.

Hypothesis 4: The more Internet knowledge the students got, the higher the level of their ability to use Internet.

\section{$B 、$ Use and gratifications}

Uses and gratifications theory combining psychological and sociological knowledge explains the behavior that audience use media to meet their needs. And the theory points out the social causes and psychological motivation that made the audience to accept the media. The hypothesis of "Use and gratifications theory" hold that the audiences are active in the process of receiving the media information and that they have a variety of needs and expectations for different levels and angles of information, such as access to information, entertainment or for social activity. If some of the audiences use certain media to satisfy their needs, or the harvest exceeded expectations, then the media would have a stronger effect on these audiences. Based on this theory, we make the following hypothesis:

Hypothesis 5: The less traditional media (including newspapers, radio, television, film) meet individual needs, the higher the level of students using the Internet.

Hypothesis 6: The more Internet meet individual needs, the higher the level of college students Internet usage.

\section{C、Self-efficacy and attitude theory}

Attitude is a person's like or dislike the tendency to an object, behavior, individual, unit, event, or the part of the personal world, we can measure user attitude towards Internet from the measurement of the Internet importance to user's life, work and study, the user's attitude towards Internet plays an important role about how to use Internet and Internet self-efficacy is associated with the attitude, which both belong to the emotional concept. While self-efficacy paying attention to the individual's confidence and judgment, Researcher defined "self-efficacy" as generalization ability ${ }^{[4]}$.. According to this theoretical framework, we make the following hypothesis:

Hypothesis 7: For college students, the higher regarding the value on the Internet, the higher the level of Internet usage

Hypothesis 8: For college students the higher regarding the self-efficacy on the Internet, the higher the level of Internet usage

\section{Methodology}

\section{A、 Dependent variable}

In this study, the analysis object is college students' second digital divide, which is the usage gap of the Internet. Therefore, dependent variable of this research includes the following two dimensions:

1, The time of Internet usage, Measurement question is that "How much average time do you spend online per day?" Internet usage time is a continuous variable. 2, Internet usage index about learning and working. 


\section{C、 Independent variable}

1, Family socio-economic background variables: (1) Parents' level of education. Father or mother received any college education and higher level $=1$; received any college education $=0$. (2) Birthplace. As the use gap of the Internet between city and non-urban becomes different, we set urban $=1$, urban and rural $=0.2$ 、 Knowledge variables. (1) Educational level (continuous variable). (2) The level of Internet knowledge. 3, The media usage to meet the needs of motivational variables: (1) Traditional media (newspapers, radio, television, movies, etc.) which could meet the needs of students. (2) Internet which could meet the needs of students 4, Attitude and self-efficacy variables, (1) Attitude toward Internet. (2) Internet self-efficacy. 5, Demographic variables. (1) Gender. $M=1$, female $=0$. (2) Age.

\section{RESULTS}

Through SPSS, we summarized table 1:

Table 1

Multiple linear regression analysis factors of dependent variables

\begin{tabular}{|c|c|c|c|c|c|}
\hline & & \multicolumn{2}{|c|}{$\begin{array}{c}\text { The time of Internet } \\
\text { usage }\end{array}$} & \multicolumn{2}{|c|}{$\begin{array}{l}\text { Internet usage index abou } \\
\text { learning and working }\end{array}$} \\
\hline & & Beta & Sig. & Beta & Sig. \\
\hline \multirow[b]{2}{*}{ Family socio-economic } & Father education & -0.04 & 0.5 & -0.07 & 0.28 \\
\hline & & & & & \\
\hline \multirow[t]{2}{*}{ background variables } & Mother education & -0.02 & 0.81 & 0.1 & 0.13 \\
\hline & Place of birth & $0.32 * *$ & 0 & -0.09 & 0.13 \\
\hline \multirow{2}{*}{ Knowledge variables } & Educational level & $-0.18 *$ & 0.01 & 0.11 & 0.11 \\
\hline & The level of Internet knowledge & 0.07 & 0.19 & 0.07 & 0.2 \\
\hline \multirow{2}{*}{$\begin{array}{l}\text { Using the media to meet } \\
\text { the demand variables }\end{array}$} & $\begin{array}{l}\text { Motivation to use traditional } \\
\text { media to meet the demand }\end{array}$ & -0.1 & 0.09 & -0.09 & 0.12 \\
\hline & $\begin{array}{l}\text { Motivation to use Internet to } \\
\text { meet the demand }\end{array}$ & -0.04 & 0.52 & $0.17 * *$ & 0.01 \\
\hline Attitude and self-efficacy & The attitude toward Internet & $0.16^{* *}$ & 0 & $0.18 * *$ & 0 \\
\hline variables & Internet self-efficacy feelings & $0.13 *$ & 0.03 & $0.24 * *$ & 0 \\
\hline \multirow{2}{*}{ Demographic variables } & Gender & -0.02 & 0.76 & $0.14 * *$ & 0.01 \\
\hline & Age & 0.04 & 0.6 & -0.04 & 0.54 \\
\hline \multicolumn{2}{|c|}{ Adjusted R Square } & \multicolumn{2}{|c|}{0.185} & \multicolumn{2}{|c|}{0.206} \\
\hline \multicolumn{2}{|r|}{$\mathrm{F}$} & \multicolumn{2}{|c|}{7.188} & \multicolumn{2}{|c|}{8.062} \\
\hline
\end{tabular}

Note: $* \operatorname{sig}(\mathrm{p})<0.05 ; * * \operatorname{sig}(\mathrm{p})<0.01$

Table 1 show that father education $(\mathrm{Sig}=0.50)$ and mother education $(\mathrm{Sig}=0.81)$ failed in the test of significance for the time of Internet usage, and for Internet usage index about learning and working of the result of variables, Father education $(\mathrm{Sig}=0.28)$ and mother education $(\mathrm{Sig}=0.13)$ did not pass the same test of significance, hypothesis 1 failed to pass testing. But place of birth $\quad(\mathrm{Sig}=0.00)$ for the time of Internet usage for students passed the test of significance. But the place of birth $(\mathrm{Sig}=0.13)$ for Internet usage index about learning and working failed to pass the test. So hypothesis 2 is tested partly. 
The educational level of college student's for the time of Internet usage Beta is -0.18 , Sig is 0.01. Although the significance test passed, the standardized regression coefficient was negative, Therefore, hypothesis 3 is not through testing, and Educational level with study, work-related Internet usage index of Beta 0.11 .Although positive, but the Sig is 0.11 ,it did not pass the significance test, therefore, hypothesis 3 does not passed. Another variable Internet professional knowledge of web-based time (Sig. $=0.19)$ and Internet usage index about learning and working $($ Sig. $=0.20)$ both had no significant effect due to variable, hypothesis 4 is not through testing.

Using traditional media predicts students the time of Internet usage (Sig. $=0.09)$ and with Internet usage index about learning and working (Sig. $=0.12$ ) had no significant effect, hypothesis 5 failed in the test. Internet usage to meet the needs predicting on college students the time of Internet usage (Sig. = 0.52) also had no significant effect, but with Internet usage index about learning and working (Sig. = 0.01 ) there are significant effects, while the beta is 0.17 , and hypothesis 6 was tested partly.

The Beta about the attitude toward Internet for the time of Internet usage is $0.16(\mathrm{Sig}=0.00)$, While The Beta about Internet usage index about learning and working o is $0.18(\mathrm{Sig}=0.00)$ Therefore, hypothesis 7 was tested. The Beta of self-efficacy about Internet usage time is $0.13,(\mathrm{Sig}=0.03)$, and The Beta of self-efficacy about Internet usage index about learning and working of is 0.24 , ( $\mathrm{Sig}=0.00)$, Therefore, hypothesis 8 was tested.

\section{CONCLUSION AND DISCUSSION}

Overall, the research shows that hypothesis 2 is partly through tested, which conducted from the theoretical framework of knowledge gaps; hypothesis 6 is partly through tested, which conducted from the theoretical framework of uses and gratifications. In this study, the most notable conclusion is that attitude and self-efficacy conducted from the theoretical framework of self-efficacy and attitude theory, the Internet self-efficacy variables were the two dependent variables have a significant impact, but also a positive correlation, hypothesis 7 and hypothesis 8 have been hypothesis tested. The attitude and self-efficacy are all emotional concept. So, the emotional factors of Internet using, including the attitude toward the Internet and the Internet self-efficacy, have great positive effects on the level of Internet usage, including the time of Internet usage and the index of Internet usage about studying and working

Of course, this study has two limitations. On the one hand, regarding the dependent variable of Internet usage index about learning and working as the second level of the digital divide is doubted. On the other hand, the limitations of this study lie in the convenience sampling method used, which limits the conclusions of the study that can be summarized as resistance.

\section{REFERENCES}

\footnotetext{
[1] Fox, S., \& Madden, M. (2005). Generations online: Pew Internet \& American Life Project.

${ }^{[2]}$ Hamburger, Y. A., \& Ben-Artzi, E. (2000). The relationship between extraversion and neuroticism and the different uses of the Internet. Computers in Human Behavior, 16, 441-449.

${ }^{[3]}$ Rojas, H., \& Shah, D. (2003). Beyond access: The digital divide and Internet uses and gratifications. IT \& Society, $1,46-72$

${ }^{[4]}$ Bandura,A.(1986).Social foundations of thought and action, Englewood Cliffs, NJ: Prentice-Hall, P391
} 